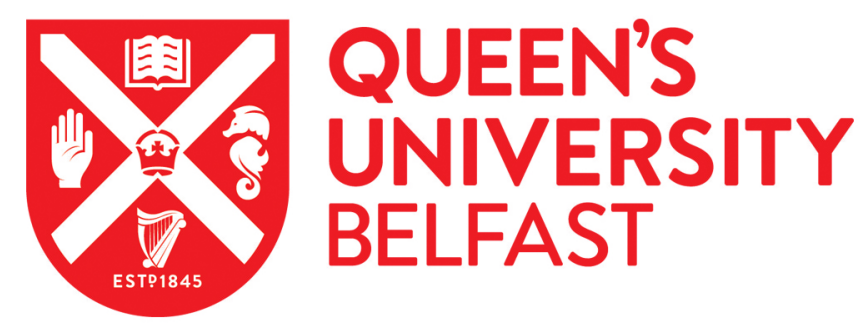

\title{
Multivariate Approach for the Authentication of Vanilla Using Infrared and Raman Spectroscopy
}

Jiménez, A. M., Tonolini, M., McAleer, O., Granato, D., Cuadros-Rodríguez, L., \& Koidis, T. (2021). Multivariate Approach for the Authentication of Vanilla Using Infrared and Raman Spectroscopy. Food Research International. https://doi.org/10.1016/j.foodres.2021.110196

Published in:

Food Research International

Document Version:

Peer reviewed version

Queen's University Belfast - Research Portal:

Link to publication record in Queen's University Belfast Research Portal

Publisher rights

Copyright 2021 Elsevier.

This manuscript is distributed under a Creative Commons Attribution-NonCommercial-NoDerivs License

(https://creativecommons.org/licenses/by-nc-nd/4.0/), which permits distribution and reproduction for non-commercial purposes, provided the author and source are cited.

\section{General rights}

Copyright for the publications made accessible via the Queen's University Belfast Research Portal is retained by the author(s) and / or other copyright owners and it is a condition of accessing these publications that users recognise and abide by the legal requirements associated with these rights.

Take down policy

The Research Portal is Queen's institutional repository that provides access to Queen's research output. Every effort has been made to ensure that content in the Research Portal does not infringe any person's rights, or applicable UK laws. If you discover content in the Research Portal that you believe breaches copyright or violates any law, please contact openaccess@qub.ac.uk. 
MULTIVARIATE APPROACH FOR THE AUTHENTICATION OF VANILLA USING INFRARED AND RAMAN SPECTROSCOPY

Ana M. Jiménez-Carvelo ${ }^{1}$, Margherita Tonolini ${ }^{2}$, Orla McAleer ${ }^{2}$, Luis Cuadros-Rodríguez ${ }^{1}$, Daniel Granato ${ }^{3}$, Anastasios Koidis ${ }^{\otimes}$

\section{(1)}

${ }^{1}$ Department of Analytical Chemistry, University of Granada, c/ Fuentenueva, s.n. E-18071 Granada, Spain.

2 Institute for Global Food Security, Queen's University, 18-30 Malone Road, Belfast BT9 $5 \mathrm{BN}$, Northern Ireland, United Kingdom.
${ }^{3}$ Food Processing and Quality, Natural Resources Institute Finland, Latokartanonkaari 9, 00790 Helsinki, Finland.

$\bowtie$ Corresponding author (e-mail: t.koidis@qub.ac.uk , tel. +44 289097 5569) 


\section{ABSTRACT}

18 Many different versions of vanilla extracts exist in the market in a variety of origins, purity levels and composition with little effective regulation. In this study, vanilla is authenticated both in terms of purity and geographical origin applying a multivariate approach using near infrared (NIR), mid infrared (MIR) and Raman spectroscopy following a complex experimental design. Partial least squares-discriminant analysis (PLS-DA) was applied to the spectral data to produce qualitative models. The prediction accuracy of the models was externally validated from the specific success/error contingencies. The results showed that MIR and Raman are reliable for authenticating vanilla in terms of purity, obtaining sensitivity, specificity, precision, and efficiency values equal to 1.00 , and Raman is especially suitable for indicating the geographical origin of vanilla extracts, achieving performance metrics around 0.9.

Keywords:; authenticity, vanilla; fingerprinting, multivariate analysis; infrared spectroscopy; Raman spectroscopy; discriminant analysis. 


\section{INTRODUCTION}

Vanilla is the second-most expensive spice worldwide, as well as the world's most popular flavouring material in the food industry. The spice derives from the orchid pods of the genus Vanilla, a native plant of Mexico. The majority of the world's vanilla ( $80 \%$ of global production) belongs to Vanilla planifolia species, commonly known as "Bourbon" vanilla, grown in Madagascar and neighbouring islands with 1000-1200 tons of cured vanilla beans exported every year (Bomgardner, 2017). The second type is Tahiti Vanilla (V. tahitensis) cultivated in French Polynesia and New Papua Guinea. Mexico, India, and Indonesia produce V. planifolia. Vanilla can be marketed in different forms, including extract, beans, and powder. The vanilla beans, which can be found inside the pods, can greatly vary in price according to their particular type/species, geographical origin and overall quality (Ranadive, 1992).

Real vanilla pods have a pure delicate and complex spicy flavour, which can be mainly attributed to the phenolic aldehyde vanillin $\left(\mathrm{C}_{8} \mathrm{H}_{8} \mathrm{O}_{3}\right)$, the latter accounts for up to $2 \%$ of the actual vanilla bean. Apart from vanillin, $p$-hydroxybenzaldehyde, guaiacol (and in the case of Tahiti vanilla, also anise alcohol) complement the main aroma profile of real vanilla (Westcott et al., 1994; Bettazzi et al., 2006; Sharma et al., 2006).

Consequently, vanilla beans are in limited global supply, and command a premium price (\$4,000/kg; Rao \& Ravishankar, 2000). This has led to development of numerous synthetic or semi synthetic products in order to minimise the cost and satisfy the demand. These products contain synthetically produced vanillin as the base ingredient. Synthetic vanillin is synthesised from ferulic acid or guaiacol (synthetic pathway) and to a lesser extend from eugenol or lignin (semi-synthetic). Most of these products also contain ethyl vanillin, coumarin or piperonal used to mimic the flavour of natural vanilla but do not naturally occur in the authentic vanilla (Sinha et al., 2008a; Huesgen, 2011a).

Both EU and USA legislation state that if a product is labelled as 'vanilla extract', it has to derive from authentic vanilla beans and should not contain any synthetic vanillin. Vanillin synthesis and the production of synthetic vanilla extracts, however, might involve the use of 
hazardous ingredients, or processes. Biotechnologically produced vanillin from the microbial enzymatic oxidation of naturally occurring 4-hydroxy-3-methoxycinnamic acid (found in rice bran), will have the same biogenic signature as the one deriving from the natural vanilla beans, so even if it is illegal to substitute with it, it is very hard to discriminate using analytical methods (Greule, Mosandl, Hamilton \& Keppler, 2015). One can understand how the complexity of the legislation around 'vanilla extracts' or 'vanilla flavouring' and the fine line between a legit and a non-legit product fuels the motivation for fraud either in the form of blending or substitution adulteration (Poole et al., 1995). The most common type of vanilla adulteration involves partly or wholly substituting vanilla flavour extracted from vanilla beans with cheaper synthetic vanillin, while labelling the result flavouring as "pure" and coming only from beans. Other types of falsification include the substitution of tonka bean extract (lower cost plant extract with a strong flavour) for some of the vanilla extract or labelling with the incorrect geographical origin of growth.

The cured vanilla bean has a complex composition, and its composition is highly affected by different climatic conditions, processing, and origins. Thus, detecting any adulteration is not an easy task. Many analytical methods have been developed for the determination of the authenticity and traceability of vanilla. Sophisticated targeted methods for traceability mainly focused on stable isotopes analysis and on elemental analysis. Gas chromatography-isotope ratio mass spectrometry (GC-IR/MS) was employed to determine $\delta^{13} \mathrm{C}$ and $\delta^{2} \mathrm{H}$ values of the vanillin from the vanilla extracts for determination the geographical origin of vanilla pods (Hansen et al., 2014). On the other hand, X-ray fluorescence spectroscopy and separately, inductive coupled plasma-mass spectroscopy (ICP-MS) were used to study the elemental composition and classify vanilla from different origins (Hondrogiannis, Rotta \& Zapf, 2013a; Hondrogiannis, Ehrlinger, Poplaski \& Lisle, 2013b). The aforementioned studies have demonstrated some success especially in species differentiation ( $V$. planifolia vs $V$. tahitensis) and in the broad geographic discriminations which is intrinsically linked to the cultivated species. More specific studies also focused on the determining the source of vanillin (natural 
vs biotechnologically produced) using site-specific natural isotope fractionation-nuclear magnetic resonance (SNIF-NMR) (Remaud, Martin, Martin, \& Martin, 1997) and specific methoxy group targeted $\delta^{13} \mathrm{C}$ and $\delta^{2} \mathrm{H}$ stable isotope analysis (Greule, Mosandl, Hamilto, \& Keppler, 2009; Greule et al., 2010).

Although it is true that authenticity is better correlated with stable isotopes and minerals/trace elements, rapid analysis is needed in the field and along the supply chain (Geibler et al., 2017; Galvin-King, Haughey, \& Elliot, 2018). Recently, the use of molecular fingerprinting techniques such as vibrational spectroscopy (infrared or Raman) is rising due to the increased sensitivity reduced cost and ease of use. In the case of herbs and spices these techniques demonstrated their potential (Galvin-King, Haughey, \& Elliot, 2018). Sharp et al. (2012) attempted to use mid infrared-attenuated total reflectance (MIR-ATR) coupled with soft independent modelling of class analogy (SIMCA) to cluster the vanilla extracts from the same origins and species. This study showed some separation between clusters of molecular signatures (representing different vanilla origins) and although concluded that MIR less powerful for discrimination due to its non-specificity, the potential of this rapid method was demonstrated. There are no studies concerning the use of other types of vibrational spectroscopy such as Near Infrared (NIR) and Raman. Based on the ease of use, speed of analysis, portability of the instrument, instrument prevalence in many industries including the food industry, as well as current demonstrated applications of all types of vibrational spectroscopy in the area of food authentication (Danezis et al., 2016), a comprehensive study evaluating their potential in vanilla authentication is missing. The aim of this study, therefore, was to develop a screening protocol for rapid evaluation of authenticity and geographical origin detection of commercial vanilla samples using IR and Raman spectroscopy. According to the design, the authenticity is evaluated based on the detection of synthetic vanillin or tonka bean extract mixed in different ratios in the vanilla sample and the origin is evaluated based on whether a vanilla sample is coming from Madagascar or not. 


\section{MATERIALS AND METHODS}

117

\subsection{Vanilla samples}

119

120

A total of 125 vanilla samples were used in this study. From them, 65 were pure vanilla from different origin geographic and 60 were mixtures of pure extract with synthetic extract vanilla prepared in the laboratory (the design and preparation of these mixtures is described in the 2.3 section). Table 1 includes details of the samples.

Table 1

The majority of the pure vanilla was acquired from trusted sourced including local authorities using overseas contacts and others were purchased either from online retailers or standard retail both in France and in the UK during the period 2018-19. The retail price range was 160$882 £ / \mathrm{kg}$ for the samples claimed to originate from Madagascar and $0.8-924 £ / \mathrm{kg}$ for the rest of the samples. Lastly, two types of vanillin were purchased, a synthetically produced $(99.9 \%$ pure, Sigma-Aldrich, Dorset, UK) and a biotechnologically produced (fermentation of natural eugenol sold by Solvay, Zurich, Switzerland) respectively. Pure tonka beans were also purchased from Sigma-Aldrich.

\subsection{Extract preparation of vanilla pods}

The vanilla pod samples were opened carefully to collect the beans, labelled and frozen ($25^{\circ} \mathrm{C}$ ) upon arrival in individual bags. After at least $24 \mathrm{~h}$, frozen beans were transferred to a freeze dryer and dried over $48 \mathrm{~h}$. The beans were removed from the freeze dryer and immediately air sealed. The dry bean samples were then grounded individually with a small laboratory grinder to a fine powder ( $5 \mathrm{~mm}$ pore sleeve was used) and transferred into airtight plastic containers. For the solid-liquid solvent extraction, $4.000 \mathrm{~g}$ of each powdered sample 
were placed in a $50 \mathrm{ml}$ tube and $25 \mathrm{ml}$ of 50:50 ethanol:water $(\mathrm{v} / \mathrm{v})$ were added. After $1 \mathrm{~min}$ of vigorous agitation, the tubes were left to macerate for $72 \mathrm{~h}$ in slow speed. The solids were separated from the extracted liquid using a centrifuge (20 min at room temperature, 2000 min $^{-}$ $\left.{ }^{1} \times \mathrm{g}\right)$. The extracts were then transferred to a pre-weighted glass tubes and dried in batches using a Turbovap at $50^{\circ} \mathrm{C}$ under a nitrogen flow. The solids were reconstituted at $3 \% \mathrm{w} / \mathrm{v}$ using the appropriate amount of $35 \%$ ethanol: water. The pure vanilla extracts were transferred to glass vials and frozen $\left(-25^{\circ} \mathrm{C}\right)$ until further analysis.

The exact same extraction procedure was used to prepare the $3 \%$ Tonka bean extracts starting from raw Tonka beans. This extract was also infused with caramel colouring $(3 \% \mathrm{w} / \mathrm{v}$ final concentration) at a later stage to make "spiked vanilla extract". Both these ingredients were added to simulate the composition and colour of real vanilla extracts.

\subsection{Experimental design and admixtures preparation}

The purity and the geographic origin of the vanilla samples were tested using two scenarios.

In the first scenario (focusing on authenticity of the vanilla) the main research question was whether the sample tested was $100 \%$ pure vanilla or it has some adulterants, namely synthetic vanillin or Tonka bean extract, often added to lower the cost and mimic the flavour of pure vanilla. For this, 107 vanilla extracts were considered, of those: a) 59 were the pure extracts (PE group, $P E=M+N M+M X$, where $M$ is the Madagascar vanilla samples, NM is the nonMadagascar samples and MX are the admixtures of these two sample categories) originating from the extraction of the vanilla beans (as per the procedure described in 2.2) - regardless of their exact geographical origin, b) 45 were vanillin-spiked vanilla extracts and c) 15 were Tonka-spiked vanilla extracts. The latter two (spiked) groups were admixtures prepared in house. More specifically, the 45 vanillin-spiked vanilla samples contained pure extracts (35$85 \%)$ mixed with synthetic vanillin $(0.03-0.13 \%)$ and caramel flavour $(0-3.5 \%)$ using 3 different 
vanilla samples (CODE) contained pure vanilla extracts $(50-90 \%)$ mixed with various amounts of caramel-infused 3\% Tonka bean extract. To prepare this set, the 3\% w/v pure Tonka bean extract (prepared as in 2.2) was infused with caramel flavour at a 95:5 w/w ratio (see Supplementary Information for more details). In total the adulterated vanilla samples were 55 (AD group).

In the second scenario (focusing on the origin), the main research question was whether the vanilla sample under investigation is coming from Madagascar or not. For this, the obtained pure vanilla extracts (see 2.2) were used to form two district groups: the $M$ group $(n=21$ samples) strictly deriving from Madagascar, the NM group (Non-Madagascar, $n=26$ samples from elsewhere) as well as certain in-house admixtures of both groups, to simulate potential adulteration of Madagascar with vanilla from other locations. More specifically, to create this admixture group (MX), 6 Madagascar and 6 Non-Madagascar extracts were randomly selected to prepare 12 simple admixtures in ratios ranging from $5-95 \%$, using each $\mathrm{N}$ and each NM vanilla extract only once. This occurred to create some variability in the dataset. More specifically, the admixtures were: 5\% 17M+ 95\% 35NM; 5\% 11M+95\% 36NM; 5\% M12 + 95\% 38NM; 10\% M9 + 90\% 23NM; 10\% M12 + 90\% 21NM; 10\% M14 + 90\% 36NM 15\% M22 + 85\% 17NM; 15\% M14 + 85\% 38NM; 20\% M17 + 80\% 20\% M11 + 80\% 21NM; 23NM; $5 \%$ M9 + 95\% 17NM; 10\% M22 + 90\% 35NM (see Supplementary Information for more details).

\subsection{MIR, NIR and Raman spectroscopy acquisition}

All samples were analysed directly as extracts in their liquid form. Measurements were performed in triplicate using all 3 types of benchtop vibrational spectroscopy in benchtop instruments using typical acquisition parameters. The mid infrared spectra were acquired using the Thermo Nicolet iS5 spectrometer (Thermo Scientific, Dublin, Ireland) coupled with ATR. The resolution was set at $4 \mathrm{~cm}^{-1}$, the frequency range at 4000 to $700 \mathrm{~cm}^{-1}$ and number of scans to 64 with $0.482 \mathrm{~cm}^{-1}$ intervals resulting in 6846 wavenumbers collected. The 
background noise was acquired before each measurement and was appropriately subtracted from the signal. The Near Infrared spectrum was acquired using the Antaris II FT-NIR (Thermo Fisher Scientific, Dublin, Ireland) in reflectance mode with a spinning module. All spectra were computed at $8 \mathrm{~cm}^{-1}$ resolution in $4 \mathrm{~mm}$ pathlength across the spectral range $3999-11998 \mathrm{~cm}^{-}$ ${ }^{1}$ with $1.5 \mathrm{~cm}^{-1}$ intervals resulting in 3022 wavenumbers collected. The spectra were recorded at ambient temperature and a total of 64 scans were acquired for each spectrum after appropriate background measurement. A DeltaNu Advantage Raman Spectrometer equipped with a $1064 \mathrm{~nm}$ laser was used to acquire the Raman spectra. The instrument was calibrated before every use with a blank vial followed by a random vial from the sample set to be tested. The laser power was set to $1000 \mathrm{~mW}$, integration time was $10 \mathrm{sec}$ and the number of spectra for each acquisition was set to 32 collecting signals from 1867 wavenumbers. In all cases the three NIR or MIR or Raman spectra were averaged in one spectrum using the respective acquisition software.

\subsection{Chemometric analysis of spectral data}

Spectra were obtained in the instrument-specific format, averaged and exported as CSV, then converted to MATLAB format (version R2013b). Before performing the multivariate analysis to any chemometric analysis, the spectra were submitted to a data processing stage of autoscaling and a variable selection was performed.

Principal component analysis (PCA), soft independent modelling by class analogy (SIMCA), partial least squares-discriminant analysis (PLS-DA) and support vector machineclassification mode (SVM-C) were built using PLS Toolbox (version 8.6.1, Eigenvector Research, Wenatchee, WA). For validation purpose of classification methods, the original data set was split into training and external validation set using the CADEX algorithm, developed by Kennard and Stone (Kennard \& Stone, 1969), and at least 30\% of the samples from each class were set to define the external validation set while the remaining samples constitutes the training set. Two authentication scenarios have been achieved attending to: (i) 
discrimination of pure vanilla/non-pure vanilla, and (ii) classification according to their geographical origin (Madagascar / Non-Madagascar). Table 2 details the samples used for each model according to the two scenarios.

Table 2

\section{RESULTS AND DISCUSSION}

\subsection{Interpretation of Spectra}

The MIR spectral features corroborate with similar studies. The broad peak at $3200-3550 \mathrm{~cm}^{-}$ ${ }^{1}$ is attributed to $\mathrm{O}-\mathrm{H}$ stretching vibrations mainly due to ethanol present in the extract; The sharp peak at $2980 \mathrm{~cm}^{-1}$ is due to $\mathrm{C}=\mathrm{C}-\mathrm{H}$, (such as those in phenols and fatty acids) whereas the shoulder peak at $2905 \mathrm{~cm}^{-1}$ is aliphatic $\mathrm{C}-\mathrm{H}$ stretching (methyl, $-\mathrm{CH}_{3}$, and methylene, $-\mathrm{CH}_{2}-$ ) of organic compounds abundant in the extracts (Moreno-Ley et al. 2019). The sharp peak at $1645 \mathrm{~cm}^{-1}$ is due to $\mathrm{C}=\mathrm{O}$ and $\mathrm{C}=\mathrm{C}$ aromatic stretching vibrations (aldehydes, ketones, esters of vanilla as well specific pyrones (Brunschwig et al., 2009). Peaks in the fingerprint region such as the 1088 and $1044 \mathrm{~cm}^{-1}$ are less specific and are attributed to stretching vibrations of the $\mathrm{C}-\mathrm{H}, \mathrm{C}-\mathrm{O}$ bonds also abundant in all plant extracts (Aljaff et al., 2013).

In general, the harmonic vibrations and overtone absorption spectra of NIR spectroscopy provide less specific information on fundamental molecular vibrations (raw data shown in Fig 3b). Absorption peaks were observed in the raw spectra at approximately $8400-8200 \mathrm{~cm}^{-1}$, (second and third C-H overtones) and the regions 6800-7250, 6200-6500 and 5700-6000 cm${ }^{1}$ overlap with the first $\mathrm{C}-\mathrm{H}$ overtone. The two peaks at $5200-4500 \mathrm{~cm}^{-1}$ fall within the region associated with $\mathrm{C}-\mathrm{H}$ and $\mathrm{O}-\mathrm{H}$ combination bands coarsely attributed to the solvent and the other organic constituents of the extracts. The spectral features broadly agree with those reported in the literature (Wongsheree et al., 2014). 
246 On the other hand, the most intense Raman bands appear in four wavenumbers or Raman

247 shifts: $877 \mathrm{~cm}^{-1}$ (low frequency carbon-carbon vibrations), $1040-1185 \mathrm{~cm}^{-1}$ double peak 248 (linked to aromatic rings), $1275 \mathrm{~cm}^{-1}, 1456 \mathrm{~cm}^{-1}\left(-\mathrm{CH}_{3}\right.$ and $-\mathrm{CH}_{2}$ - deformations). There are no other studies that reported Raman spectral features of vanilla extracts or vanilla powder although the observed vibration patterns of the spectra are in line with Raman spectra of similar herbs and spices (Galvin-King et al., 2018). The MIR and Raman spectral features of the vanilla extracts are shown in Figure 1.

Figure 1

\subsection{Selection of variables by means on principal component analysis}

257

When working with instrumental fingerprints it is common to have a data set, characterised by thousands of variables, that is too large so long computational times are required to build the classification model. For this reason, a selection of variables to reduce the dimensionality of the data is commonly applied. Usually two ways of selecting the region of interest are based on: a) selecting a specific number of raw variables by implementing variable section methods, such as interval partial least-squares regression (iPLS), genetic algorithms (GA) or variable importance in projection (VIP), or b) generating new variables, which are usually a combination of the raw variables, for example when hierarchical cluster analysis (HCA) or PCA are employed as tool to reduce the dimensionality of data and not as techniques of exploratory analysis.

In this work PCA has been employed as technique of exploratory analysis and, in addition variable selection was performed examining the PCA loading plot for each data set acquired by NIR, MIR and Raman. The region of interest selected was a selection of the relevant raw 
270 variables of the spectra. For that purpose, the regions of the spectra where the intensity of the

271 loading was high were selected.

272 Initially, a PCA model from NIR data was developed with four principal components (PCs)

273 which explain $97.51 \%$ of the variance (see Figure 2). In this case, PCA allowed to visualize

274 the two groups of samples which are correlated with adulterated vanilla (positive scores in

275 PC2) and pure extract of vanilla (negative scores in PC2). Then, the distribution of the loadings

276 was examined to understand the groupings observed in the scores plot, to select the region

277 of interest (ROI) of the NIR spectra. Figure 3 shows both the PC2 loading plot, aligned on the

278 NIR spectra from two samples of pure and non-pure vanilla. The profile from the PC2 loading

279 plot shows a sharp and intense boosting and busting which corresponds to the central peak

280 of the spectrum (5926-6890 $\mathrm{cm}^{-1}$ ) and is defining of the ROI from which the PC2 which sets the spacing between the two groups is principally composed.

Figure 2

283

\section{Figure 3}

For the PCA model from Raman dataset four principal components were selected which explain $99.92 \%$ of the variance (see figure 4). In this case no groupings were observed. The PCA loadings shown the same shape than the Raman spectra, thus no region of interest was selected (see figure 5). Although the initial region of the Raman spectrum $\left(200-777 \mathrm{~cm}^{-1}\right)$ shows a high loading value, it was not finally selected since this part corresponds with fluorescence interference and it was not considered. Therefore, only the $778-1549 \mathrm{~cm}^{-1}$ range was employed for the development of the classification methods.

Figure 4 
Figure 5

294

295 In the case of the data from MIR, PCA model was built with 7 PCs that explained a $95.54 \%$ of the variance. As can be observed in Figure 6 there is a grouping pattern of the pure vanilla samples with negative scores for PC1 and positive scores for PC2 whereas that the non-pure samples are distributed with scores positives for PC1 and positive and negative scores for PC2. Then, when PCA loading plots were examined was not possible to select a specific region of interest since the entire loading signal shown similar importance for the grouping pattern of both sample dataset. Therefore, for the development of the multivariate classification models the entire MIR signal was used.

\subsection{Scenario 1: Purity (discrimination between pure and non-pure vanilla)}

The classification rule was based on setting the boundaries for the different classes defined ('Pure' and 'Non-pure') by the corresponding training sample dataset. Three classification methods, SIMCA, PLS-DA and SVM-C, were compared. The classification threshold for each class was established by the software.

For each classification method, three models were built from NIR, MIR and Raman dataset. The 'Pure' class was defined by value equal to 0 , while the 'Non-pure' class was defined by a value of 1 . In all cases, the PLS-DA method provided the best results. Table 3 shows the numbers of LVs chosen for each model, and Table 4 shows the quality performance metrics for the three binary classification methods, calculated according to the external validation set using the success/errors contingency for each class and for the three techniques (see supplementary Information for the classification and loading plots). 
Table 3

\section{Table 4}

320 MIR and Raman models correctly classified all samples. All the vanilla samples from 'Pure' 321 class were well classified (probability $=0$ ) and the samples from the 'Non-pure' class were also classified correctly (probability $=1$ ). Thus, all the quality metrics of the models were equal to 1.00 what involves this method could be considered reliable for authenticating the purity of vanilla samples.

Conversely, the results of the NIR model were remarkably worse than the last ones, obtaining values of sensitivity, specificity, and precision of $0.82,0.72$ and 0.76 for the 'Pure' class and $0.72,0.89$ and 0.87 for the 'Non-pure' class, respectively. Seven vanilla samples were misclassified. Two samples of the class 'Pure' were classified as 'Non-pure', and the rest of samples from 'Non-pure' class were incorrectly classified as belonging to 'Pure' class.

\subsection{Scenario 2: Geographical origin (classification according to Madagascar/Non-} Madagascar origin)

The same classification methodology was used to build the different PLS-DA multivariate classification models. The 'Madagascar' class was defined by value equal to 0 , while the 'NonMadagascar' class was defined by a value of 1 . Table 5 shows the numbers of LVs chosen for each model, and Table 6 shows the quality performance metrics for the three binary classification methods (see supplementary Information the loading plots).

Table 5 
Table 6

341 In this scenario NIR and MIR were not useful to discriminate vanilla samples from Madagascar origin. NIR and MIR achieved high classification errors of the $56 \%$ and $38 \%$ respectively, which is reflected in the performance classification metrics values shown in the Table 6 for both techniques. By contrast, Raman classified correctly almost all samples except one sample from 'Madagascar' considered as 'Non-Madagascar'. The sensitivity, specificity and precision of the model were equal to $0.86,1.00$ and 1.00 for the 'Madagascar' class and 1.00, 0.86 and 0.89 for 'Non-Madagascar' class, respectively.

The results indicate that the main chemical composition of vanilla is not strongly dependent on the geographical origin and therefore the vibrational analytical signals are not enough different to be able to make a right effective discrimination. Possibly, the differences could be focused on some minority compounds whose presence or concentration does not greatly influences the spectra.

\section{CONCLUSIONS}

This work proposes a useful methodology to rapidly authenticate the purity of vanilla extracts applying a comprehensive multivariate analytical approach considering the different compositions of fraudulent vanilla extracts. To this end, different modes of vibrational spectroscopy (NIR, MIR and Raman) have been explored. The PLS-DA classification method is the one which produces the best results. It performs well when the composition of the fraudulent samples is different from the original extract and is not sensitive enough to determine, for example, differences between biotechnologically produced vanillin and the native variant present in the vanilla pod. It can however distinguish the "gross offenders" such as spiking with tonka beans, caramel, and other additions because the difference on spectral 
364 signal can be discriminative between different samples. It is therefore useful as a screening

365 method to be used by the spice industry and retailers because access to equipment and the 366 measurement is low cost and generally accessible.

367 In addition, the same multivariate analytical approach maybe be also able to identify the 368 geographical origin of a vanilla extract, namely if it is from Madagascar or not. Geographical 369 origin is more complex analytical problem with many factors including the vanilla species also 370 playing a major role, which was not explored in this study. There is room for other more 371 sophisticated methods such as DNA fingerprinting. Further chemometric classification model 372 based on larger datasets and diversity in the samples used, representing global vanilla supply 373 and multi-year sampling, would improve model robustness and general accuracy of the 374 analytical method. 


\section{References}

Bettazzi, F., Palchetti, I., Sisalli S., Mascini M. (2006). A disposable electrochemical sensor for vanillin detection. Analytica Chimica Acta, 55: 134-138. https://doi.org/10.1016/j.aca.2005.08.069

Bomgardner, M. (2017). The problem with vanilla | September 12, 2016 Issue - Vol. 94 Issue 36 | Chemical \& Engineering News. [online] Cen.acs.org. Available at: http://cen.acs.org/articles/94/i36/problem-vanilla.html [Accessed 6/9/2020].

Danezis, G.P., Tsagkaris, A.S., Camin, F., Brusic, V., \& Georgiou, C.A. (2016). Food authentication: Techniques, trends \& emerging approaches. Trends in Analytical Chemistry, 85, 123-132. https://doi.org/10.1016/j.trac.2016.02.026

Food and Drug Administration - FDA (2019). Code of Federal Regulations Title 21, Vol. 3. https://www.accessdata.fda.gov/scripts/cdrh/cfdocs/cfcfr/CFRSearch.cfm?CFRPart=189\&showFR=1 [Accessed 6/9/2020]

Galvin-King, P., Haughey, S.A., \& Elliott, C.T. (2018). Herb and spice fraud; the drivers, challenges and detection. Food Control, 88, 85-97.

https://doi.org/10.1016/j.foodcont.2017.12.031

Geibler, K., Greule, M., Schafer, U., Hans, J., Geibler, T., Meier, L., Keppler, F., \& Krammer, G. (2017). Vanilla authenticity control by DNA barcoding and isotope data aggregation. Flavour and Fragance Journal, 32 (4), 228-237. https://doi.org/10.1002/ffj.3379

Greule, M., Mosandl, A., Hamilton, J.T.G., \& Keppler, F. (2009). A simple rapid method to precisely determine $13 \mathrm{C} / 12 \mathrm{C}$ ratios of plant methoxyl groups. Rapid Communications in Mass Spectrometry, 23, 1710-1714. https://doi.org/10.1002/rcm.4057

Greule, M., Mosandl, A., Hamilton, J.T.G., \& Keppler, F. (2015). Comment on authenticity and traceability of vanilla flavors by analysis of stable isotopes of carbon and hydrogen. Journal of Agricultural and Food Chemistry, 63, 5305-5306. https://doi.org/10.1021/jf506172q

Greule, M., Tumino, L.D., Kronewald, T., Hener, U., Schleucher, J., Mosandl, A., \& Keppler, F. (2010). Improved rapid authentication of vanillin using $\delta 13 \mathrm{C}$ and $\delta 2 \mathrm{H}$ values. European Food Research and Technology, 231, 933-941.

https://doi.org/10.1007/s00217-010-1346-z 
Hansen, A.M.S., Fromberg, A., \& Frandsen, H.L. (2014). Authenticity and traceability of vanilla flavors by analysis of stable isotopes of carbon and hydrogen. Journal of Agricultural and Food Chemistry, 62(42), 10326-10331.

https://doi.org/10.1021/jf503055k

Hondrogiannis, E., Rotta, K., \& Zapf, C.M. (2013). The use of wavelength dispersive X-ray fluorescence in the identification of the elemental composition of vanilla samples and the determination of the geographic origin by discriminant function analysis. Journal of Food Science, 78(3), C395-C401. https://doi.org/10.1111/1750-3841.12050

Hondrogiannis, E.M., Ehrlinger, E., Poplaski, A., \& Lisle, M. (2013). Use of laser ablationinductively coupled plasma-time of flight-mass spectrometry to identify the elemental composition of vanilla and determine the geographic origin by discriminant function analysis. Journal of Agricultural and Food Chemistry, 61(47), 11332-11337. https://doi.org/10.1021/jf4025536

Huesgen, A.G. (2011). Analysis of Natural And Artificial Vanilla Preparations. Application Notes. $1^{\text {st }}$ ed. Germany: Agilent Technologies, Inc. Web. 17 Feb. 2017. [Accessed 6/9/2020]

Kennard, R.W., \& Stone, L.A. (1969). Computer aided design of experiments. Technometrics ,11, 137-148. http://doi.org/10.1080/00401706.1969.10490666

Poole, S.K., Kiridena, W., Miller, K.G., \& Poole, C.F. (1995). Planar chromatographic methods for determination of the quality of spices and flavours as exemplified by cinnamon and vanilla. Journal of Planar Chromatography, 8, 257-268.

Ranadive, A.S. (2005). Vanilla cultivation. In: Vanilla: The first international congress. Princeton: NJ: Allured, Carol Stream. p 25-32.

Rao, S.R., \& Ravishankar, G. A. (2000). Vanilla flavour: Production by conventional and biotechnological routes. Journal of the Science of Food and Agriculture, 80: 289-304. https://doi.org/10.1002/1097-0010(200002)80:3<289::AID-JSFA543>3.0.CO;2-2

Remaud, G.S., Martin, Y.L., Martin, G.G. \& Martin, G.J. (1997). Detection of sophisticated adulterations of natural vanilla flavors and extracts: application of the SNIF-NMR method to vanillin and p-hydroxybenzaldehyde. Journal of Agricultural and Food Chemistry, 45, 859-866. https://doi.org/10.1021/jf960518f

Sharma, A., Verma, S.C., Saxena N., Chadda, N., Singh, N.P., \& Sinha A.K. (2006). Microwave and ultrasound-assisted extraction of vanillin and its quantification by high- 
performance liquid chromatography in Vanilla planifolia. Journal of Separation Science, 29: 613-619. https://doi.org/10.1002/jssc.200500339

Sharp, M.D., Kocaoglu-Vurma, N.A., Langford, V., Rodriguez-Saona, L.E., \& Harper, W.J. (2012). Rapid discrimination and characterization of vanilla bean extracts by attenuated total reflection infrared spectroscopy and selected ion flow tube mass spectrometry. Journal of Food Science, 77(3), C284-C292.

https://doi.org/10.1111/j.1750-3841.2011.02544.x

Sinha, A.K., Sharma, U.K., \& Sharma, N. (2008). A comprehensive review on vanilla flavor: Extraction, isolation and quantification of vanillin and other constituents. International Journal of Food Sciences and Nutrition 59(4): 299-326.

https://doi.org/10.1080/09687630701539350

Westcott, R.J., Cheetham, P.S.J., \& Arraclough, A.J.B. (1994). Use of organized viable vanilla plant aerial roots for the production of natural vanillin. Phytochemistry, 35: 135138. https://doi.org/10.1016/S0031-9422(00)90521-1.

Aljaff, P., Rasheed, B. O., \& Omer, T. A. (2013). A comparison between natural and synthetic food flavoring extracts using infrared spectra and optical activity. Journal of Applied Physics, 5(3), 1-6.

Brunschwig, C., Collard, F. X., Bianchini, J. P., \& Raharivelomanana, P. (2009). Evaluation of chemical variability of cured vanilla beans (Vanilla tahitensis and Vanilla planifolia). Natural product communications, 4(10), 1934578X0900401016.

Moreno-Ley, C. M., Hernández-Martínez, D. M., Osorio-Revilla, G., Tapia-Ochoategui, A. P., Dávila-Ortiz, G., \& Gallardo-Velázquez, T. (2019). Prediction of coumarin and ethyl vanillin in pure vanilla extracts using MID-FTIR spectroscopy and chemometrics. Talanta, 197, 264-269.

Wongsheree, T., Rittiron, R., Wongs-Aree, C. and Thongtheing, T. (2016). Vanilla content evaluation in cured bean by near-infrared technique. Acta Horticulure 1119, 297-304 DOI: 10.17660/ActaHortic.2016.1119.41 
TABLES

379

380 Table 1. Types of vanilla samples analysed

381

\begin{tabular}{lcl}
\hline Type of vanilla & № & Origin \\
\hline $\begin{array}{l}\text { Pure Extract } \\
\text { (V. planifolia and } V \text {. tahitensis) }\end{array}$ & 53 & Madagascar (19) \\
Blends of pure extract ${ }^{1}$ & 12 & Not considered \\
$\begin{array}{l}\text { Mixture of pure extract with synthetic } \\
\text { extract }\end{array}$ & 60 & Not considered \\
\hline
\end{tabular}

${ }^{1}$ Blends of pure extract from Madagascar and non-Madagascar

382 
Table 2. Distribution of the samples used in the different classification models.

384

\begin{tabular}{lcccc}
\hline \multirow{2}{*}{ Dataset } & \multicolumn{2}{c}{ Scenario 1: Purity } & \multicolumn{2}{c}{ Scenario 2: Origin } \\
& Pure & Non-Pure & Madagascar & Non-Madagascar \\
\hline Training set & 44 & 44 & 12 & 27 \\
Validation set & 19 & 18 & 7 & 7 \\
\hline
\end{tabular}

385

386 
Table 3. Characteristics of the PLS-DA models for the Scenario 1: Purity

388

\begin{tabular}{ccccccc}
\hline & NIR & \multicolumn{2}{c}{ MIR } & \multicolumn{2}{c}{ Raman } \\
LVs & \% var & LVs & \% var & LVs & \% var \\
\hline 4 & 98.23 & 7 & 92.95 & 3 & 97.75 \\
\hline
\end{tabular}

389

390 
Table 4. Classification performance metrics of the PLS-DA model for the Scenario 1: Purity

\begin{tabular}{|c|c|c|}
\hline Performance metrics & Pure & Non-Pure \\
\hline \multicolumn{3}{|l|}{$\operatorname{NIR}\left(5926-6890 \mathrm{~cm}^{-1}\right)$} \\
\hline Sensitivity (or Recall) & 0.89 & 0.72 \\
\hline Specificity & 0.72 & 0.89 \\
\hline Positive predictive value (Precision) & 0.76 & 0.87 \\
\hline Negative predictive value & 0.87 & 1.00 \\
\hline Youden index & 0.61 & 0.61 \\
\hline Positive likelihood rate & 3.20 & 6.50 \\
\hline Negative likelihood rate & 0.15 & 0.31 \\
\hline F-measure & 0.82 & 0.79 \\
\hline Discriminant power & 0.73 & 0.73 \\
\hline Efficiency (or Accuracy) & 0.81 & 0.81 \\
\hline AUC (Correctly classified rate) & 0.81 & 0.81 \\
\hline Matthews correlation coefficient & 0.62 & 0.62 \\
\hline Kappa coefficient & 0.61 & 0.61 \\
\hline \multicolumn{3}{|l|}{$\operatorname{MIR}\left(700-4000 \mathrm{~cm}^{-1}\right)$} \\
\hline Sensitivity (or Recall) & 1.00 & 1.00 \\
\hline Specificity & 1.00 & 1.00 \\
\hline Positive predictive value (or Precision) & 1.00 & 1.00 \\
\hline Negative predictive value & 1.00 & 1.00 \\
\hline Youden index & 1.00 & 1.00 \\
\hline Positive likelihood rate & - & - \\
\hline Negative likelihood rate & 0.00 & 0.00 \\
\hline F-measure & 1.00 & 1.00 \\
\hline Discriminant power & - & - \\
\hline Efficiency (or Accuracy) & 1.00 & 1.00 \\
\hline AUC (Correctly classified rate) & 1.00 & 1.00 \\
\hline Matthews correlation coefficient & 1.00 & 1.00 \\
\hline Kappa coefficient & 1.00 & 1.00 \\
\hline
\end{tabular}


395

\begin{tabular}{l|c|c}
\hline Performance metrics & Pure & Non-Pure \\
\hline \multicolumn{1}{c|}{ Raman $\left(778-1549 \mathrm{~cm}^{-1}\right)$} & & \\
Sensitivity (or Recall) & 1.00 & 1.00 \\
Specificity & 1.00 & 1.00 \\
Positive predictive value (or Precision) & 1.00 & 1.00 \\
Negative predictive value & 1.00 & 1.00 \\
Youden index & 1.00 & 1.00 \\
Positive likelihood rate & - & - \\
Negative likelihood rate & 0.00 & 0.00 \\
F-measure & 1.00 & 1.00 \\
Discriminant power & - & - \\
Efficiency (or Accuracy) & 1.00 & 1.00 \\
AUC (Correctly classified rate) & 1.00 & 1.00 \\
Matthews correlation coefficient & 1.00 & 1.00 \\
Kappa coefficient & 1.00 & 1.00 \\
\hline
\end{tabular}

The hyphen "-" is signifying that the performance feature cannot be determined. 
Table 5. Characteristics of the PLS-DA models for the Scenario 2: Origin

398

\begin{tabular}{ccccccc}
\hline & NIR & & \multicolumn{2}{c}{ MIR } & \multicolumn{2}{c}{ Raman } \\
LVs & \% var & LVs & \% var & LVs & $\%$ var \\
\hline 3 & 97.07 & 9 & 96.73 & 2 & 99.72 \\
\hline
\end{tabular}

399 


\begin{tabular}{|c|c|c|}
\hline Performance metrics & Madagascar & Non-Madagascar \\
\hline \multicolumn{3}{|l|}{ NIR $\left(3999-11998 \mathrm{~cm}^{-1}\right)$} \\
\hline Sensitivity (or Recall) & 0.29 & 0.50 \\
\hline Specificity & 0.50 & 0.29 \\
\hline Positive predictive value (or Precision) & 0.33 & 0.44 \\
\hline Negative predictive value & 0.44 & 1.00 \\
\hline Youden index & -0.21 & -0.21 \\
\hline Positive likelihood rate & 0.57 & 0.70 \\
\hline Negative likelihood rate & 1.43 & 1.75 \\
\hline F-measure & 0.31 & 0.47 \\
\hline Discriminant power & -0.22 & -0.22 \\
\hline Efficiency (or Accuracy) & 0.40 & 0.40 \\
\hline AUC (Correctly classified rate) & 0.39 & 0.39 \\
\hline Matthews correlation coefficient & -0.22 & -0.22 \\
\hline Kappa coefficient & -0.22 & -0.22 \\
\hline \multicolumn{3}{|l|}{$\operatorname{MIR}\left(700-4000 \mathrm{~cm}^{-1}\right)$} \\
\hline Sensitivity (or Recall) & 0.57 & 0.63 \\
\hline Specificity & 0.63 & 0.57 \\
\hline Positive predictive value (or Precision) & 0.57 & 0.63 \\
\hline Negative predictive value & 0.63 & 1.00 \\
\hline Youden index & 0.20 & 0.20 \\
\hline Positive likelihood rate & 1.52 & 1.46 \\
\hline Negative likelihood rate & 0.69 & 0.66 \\
\hline F-measure & 0.57 & 0.63 \\
\hline Discriminant power & 0.19 & 0.19 \\
\hline Efficiency (or Accuracy) & 0.60 & 0.60 \\
\hline AUC (Correctly classified rate) & 0.60 & 0.60 \\
\hline Matthews correlation coefficient & 0.20 & 0.20 \\
\hline Kappa coefficient & 0.20 & 0.20 \\
\hline
\end{tabular}




\begin{tabular}{|c|c|c|}
\hline Performance metrics & Madagascar & Non-Madagascar \\
\hline \multicolumn{3}{|l|}{$\operatorname{Raman}\left(778-1549 \mathrm{~cm}^{-1}\right)$} \\
\hline Sensitivity (or Recall) & 0.86 & 1.00 \\
\hline Specificity & 1.00 & 0.86 \\
\hline Positive predictive value (Precision) & 1.00 & 0.89 \\
\hline Negative predictive value & 0.89 & 1.00 \\
\hline Youden index & 0.86 & 0.86 \\
\hline Positive likelihood rate & - & 7.00 \\
\hline Negative likelihood rate & 0.14 & 0.00 \\
\hline F-measure & 0.92 & 0.94 \\
\hline Discriminant power & - & - \\
\hline Efficiency (or Accuracy) & 0.93 & 0.93 \\
\hline AUC (Correctly classified rate) & 0.93 & 0.93 \\
\hline Matthews correlation coefficient & 0.87 & 0.87 \\
\hline Kappa coefficient & 0.86 & 0.86 \\
\hline
\end{tabular}

The hyphen "-" is signifying that the performance feature cannot be determined. 
Figure 1. Raw spectra of all vanilla extracts by (a) MIR and (b) Raman.

409

410 Figure 2. PCA scores plot in PC1-PC2 plane for pure and non-pure vanilla samples from NIR 411 data.

412

413 Figure 3. (a) PC2 loading plot of all vanilla samples and (b) superposed NIR spectra from 414 two vanilla samples (one pure and other non-pure) zooming the region of interest selected.

415

416 Figure 4. PCA scores plot in PC1-PC2 plane for pure and non-pure vanilla samples from 417 Raman data.

418

Figure 5. (a) Loading plot of all vanilla samples and (b) Raman spectrum of a pure vanilla sample.

421

422 Figure 6. PCA scores plot in PC1-PC2 plane for pure and non-pure vanilla samples from MIR 423 data.

424 
(a)

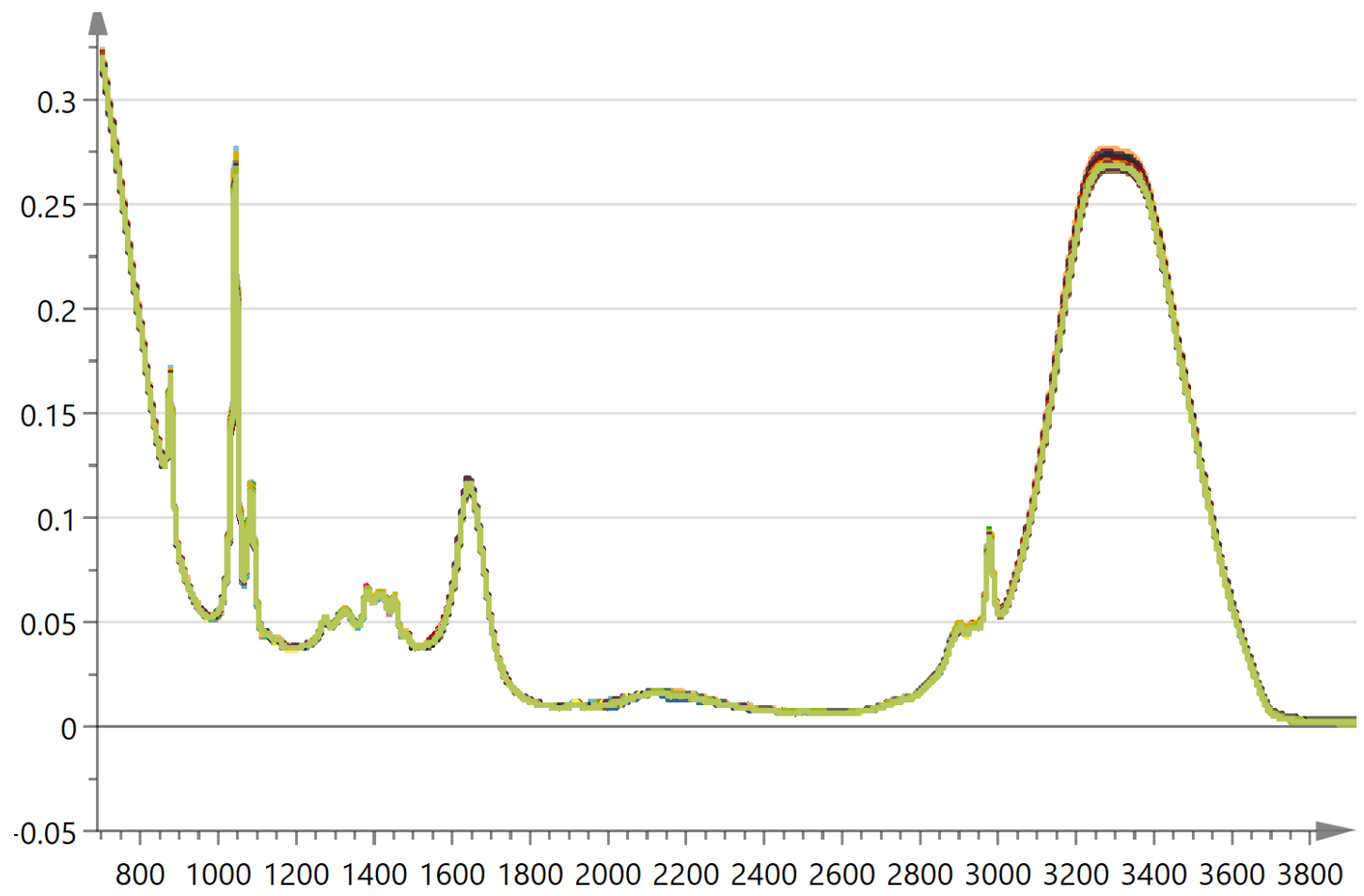

(b)

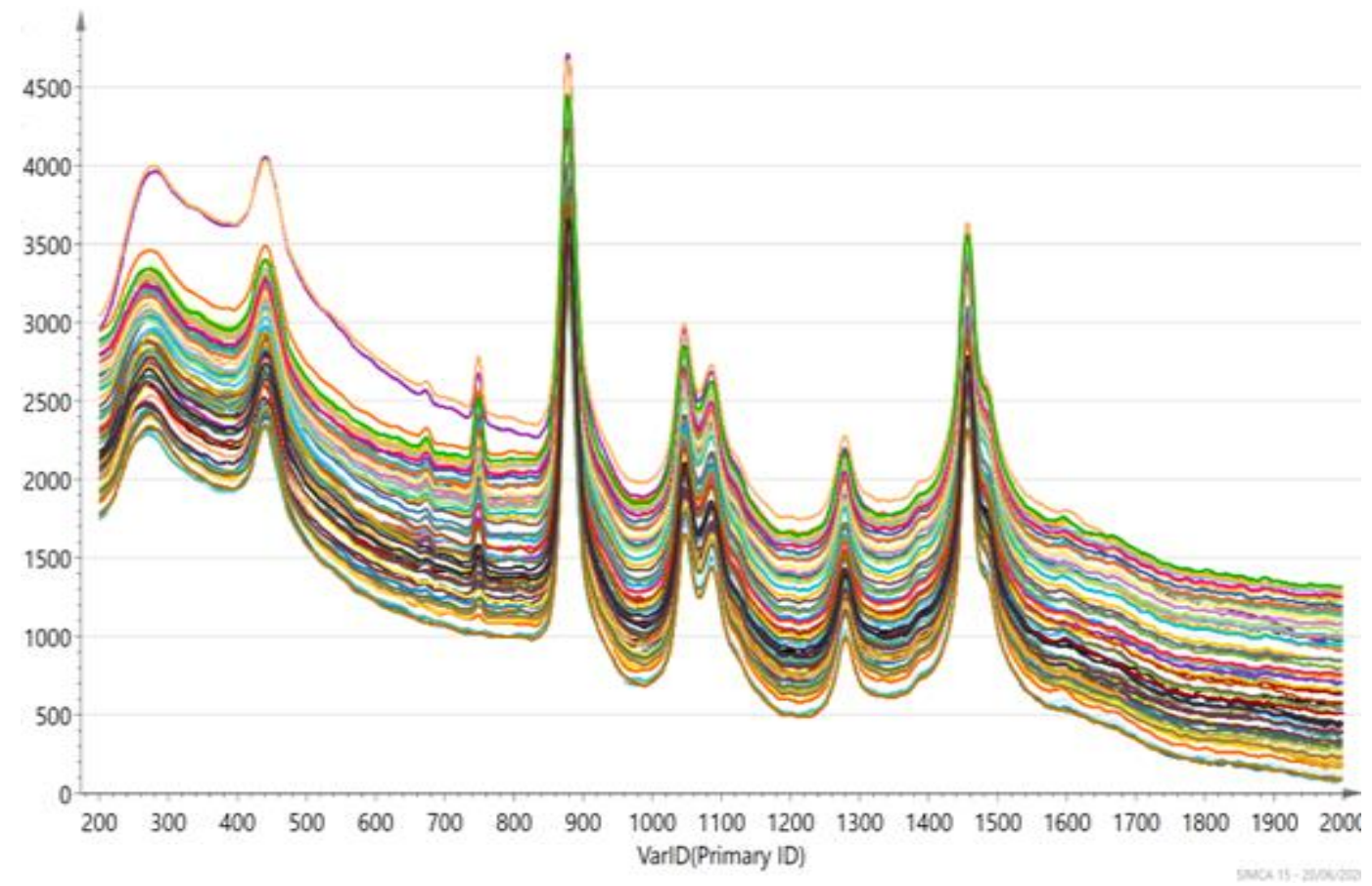


429

430

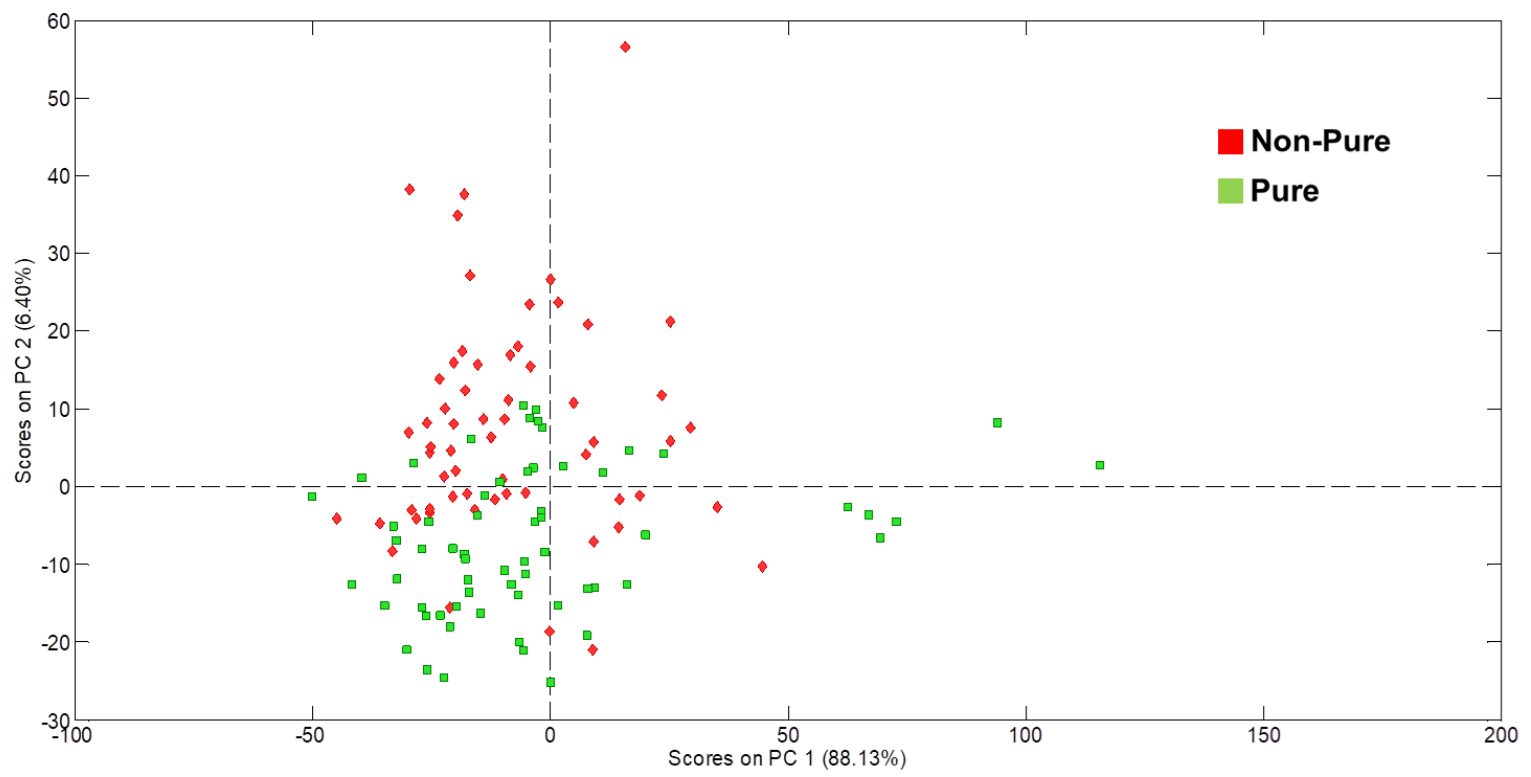

431

432 
433 <Figure 3>

434

(a)

(b)

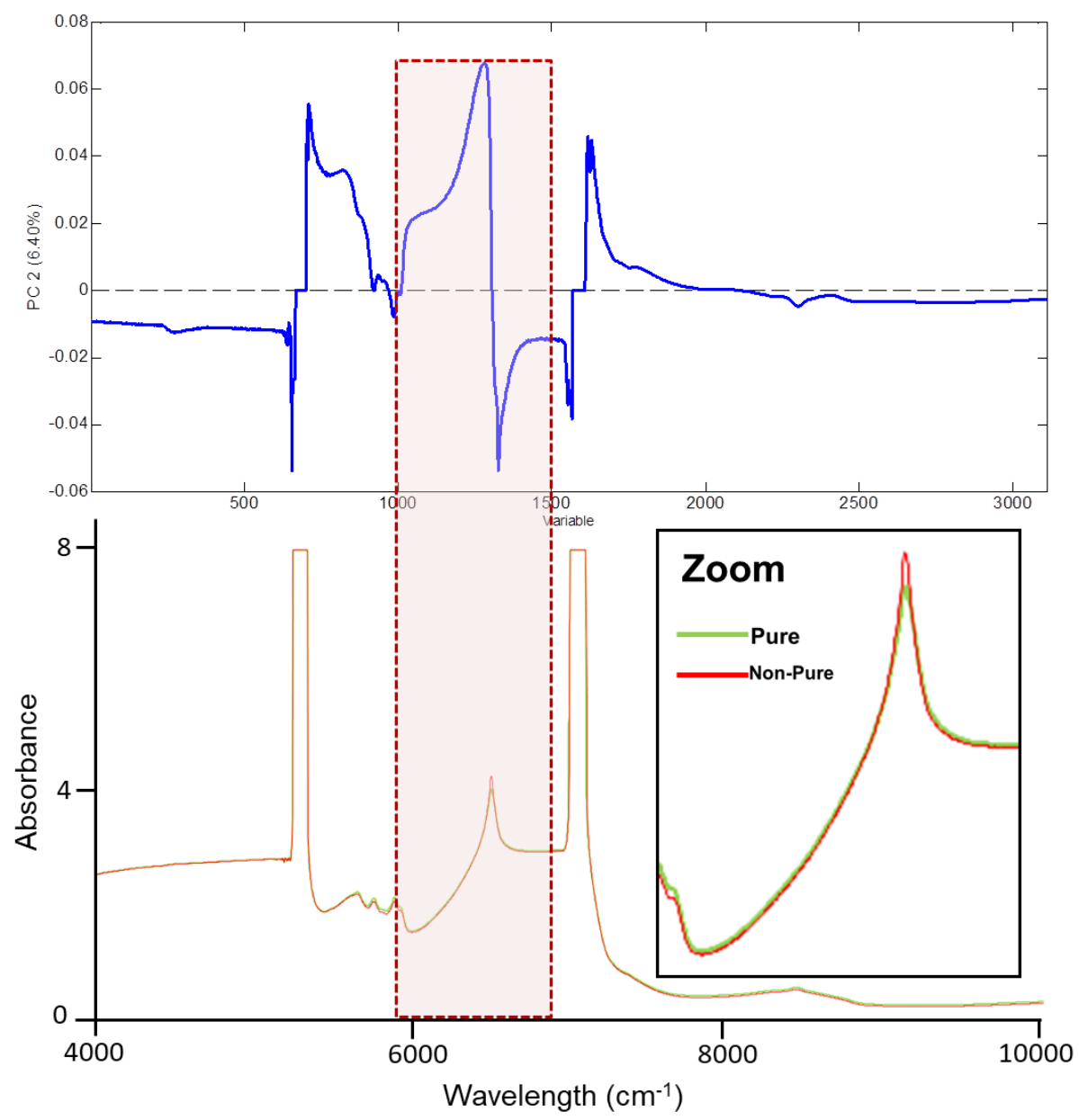

435

436 

$<$ Figure 4>

438

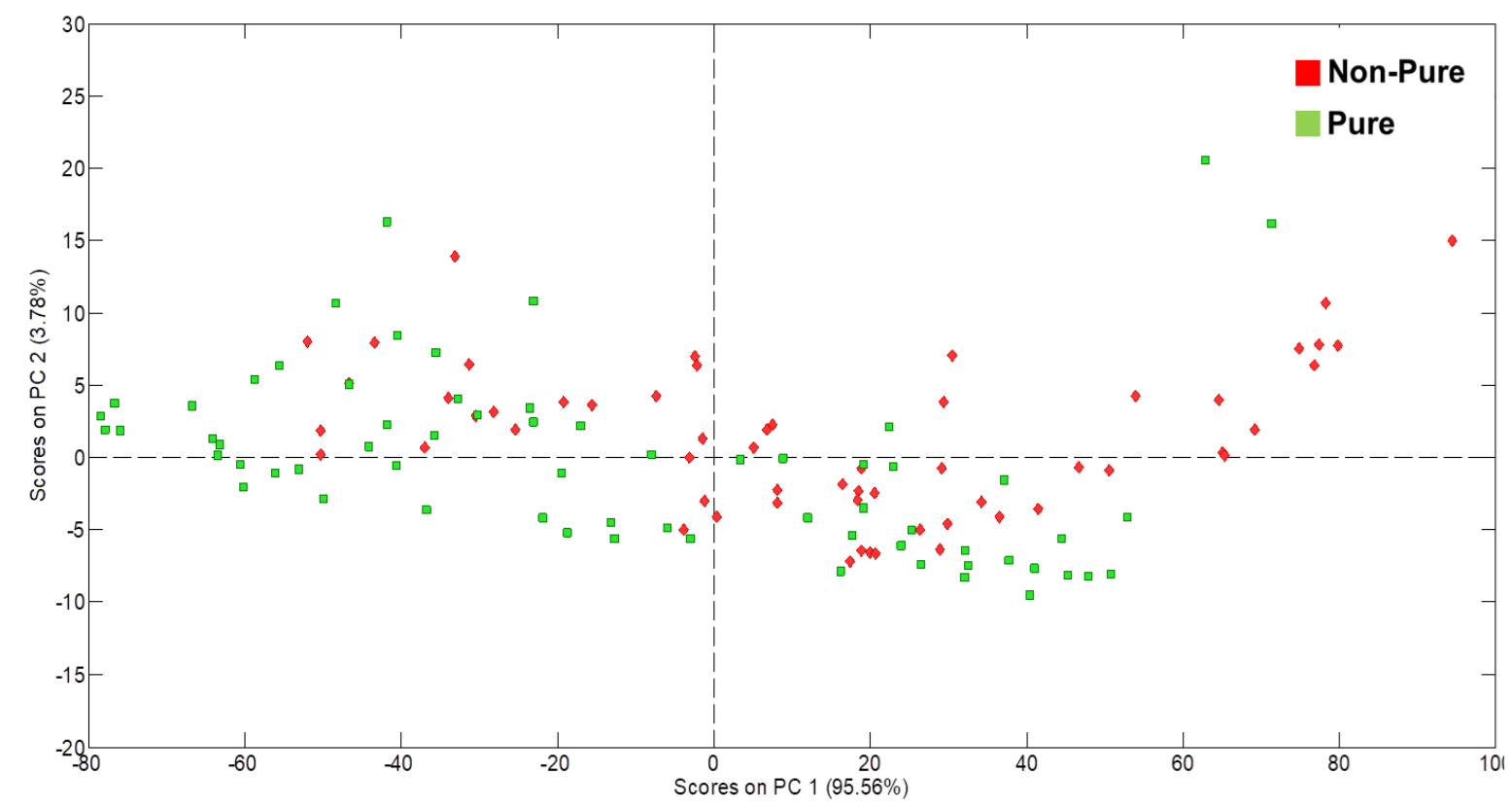

439

440 
$441<$ Figure 5>

442

(a)

(b)

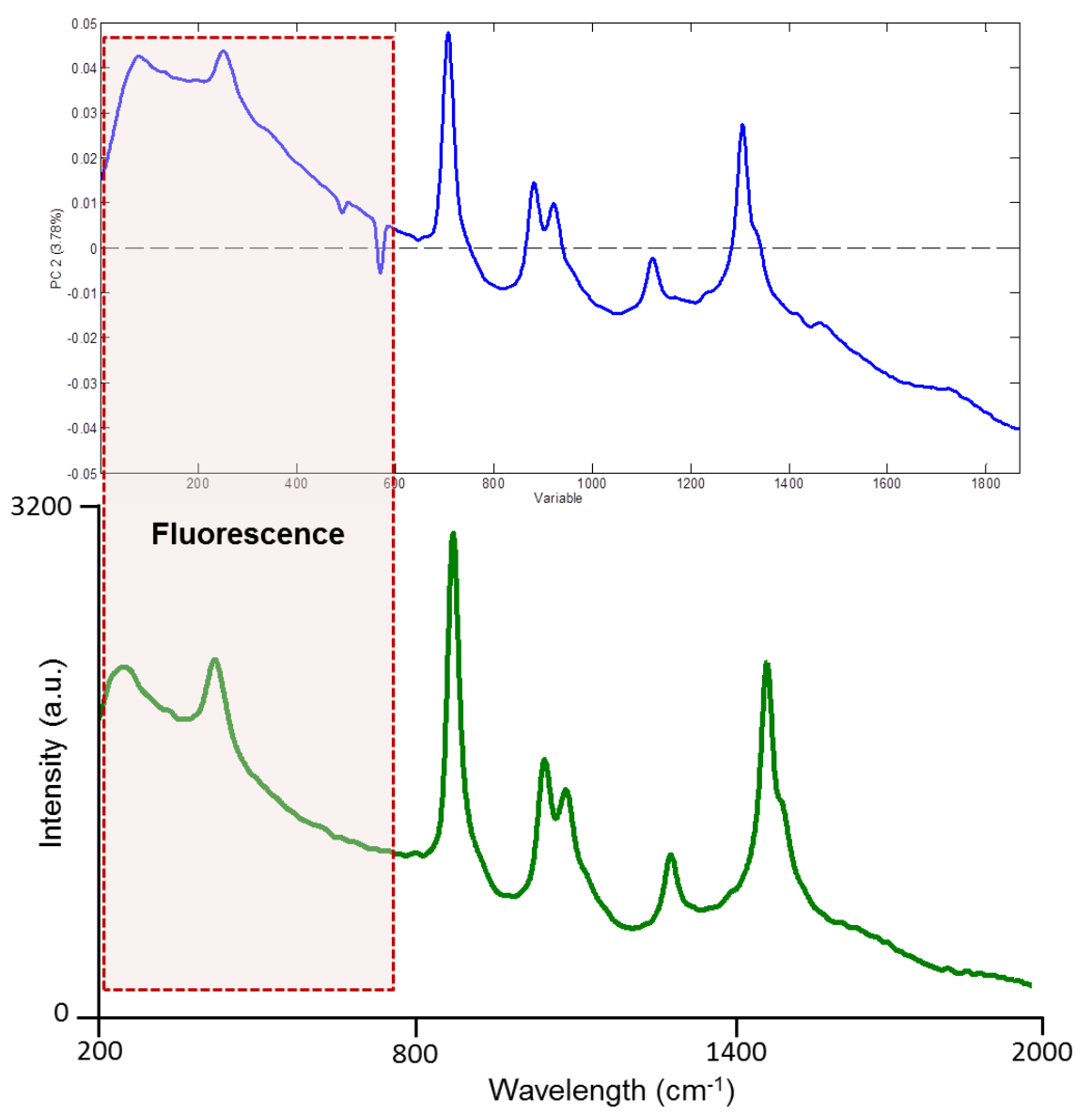

443 
$445<$ Figure 6>

446

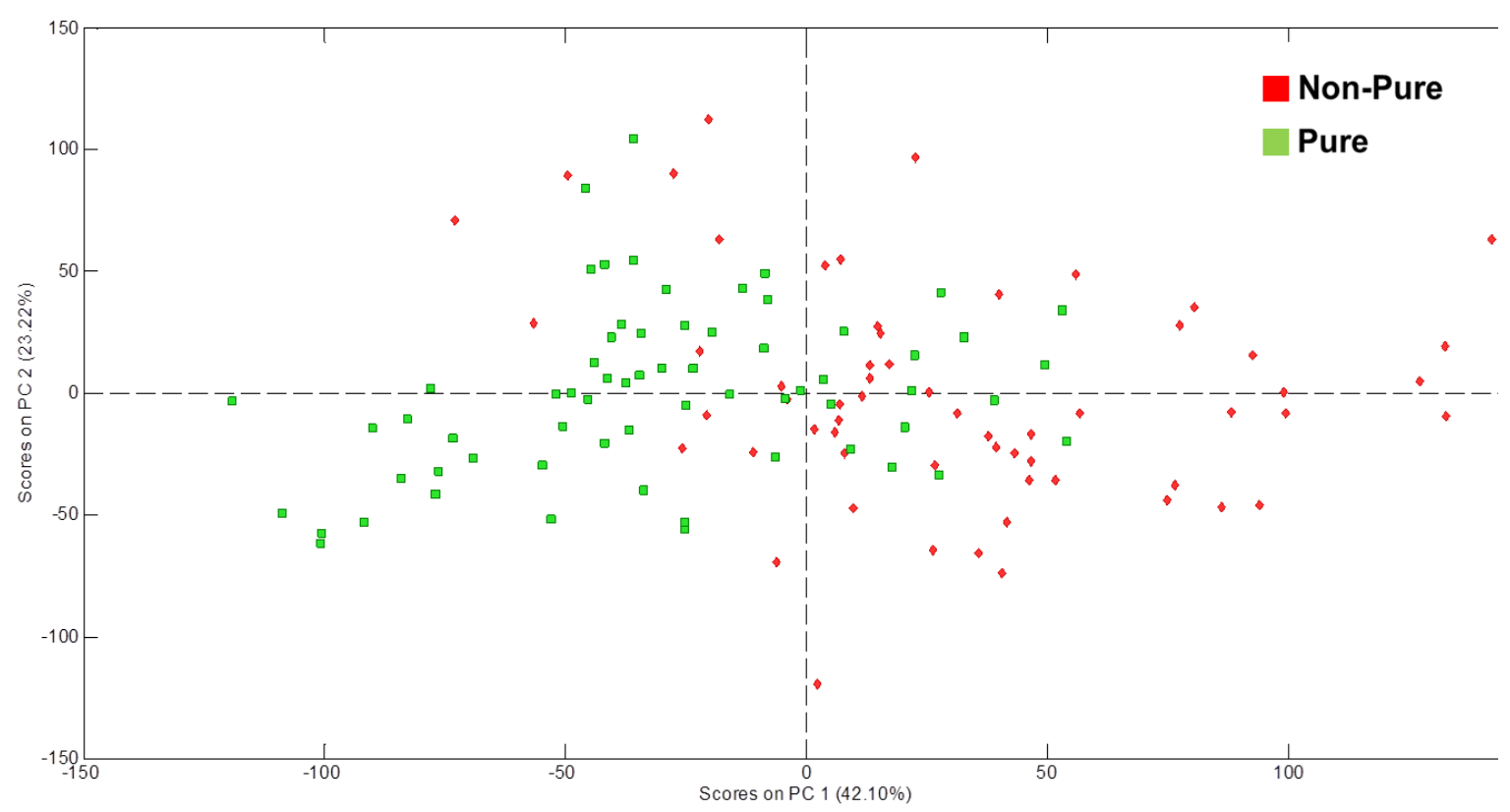

447

448 
450 Concentrations of in-house mixtures

451 The following tables show the varying ratios the in-house mixtures were made to.

452 The admixtures were prepared by selecting 6 Madagascar and 6 Non-Madagascar extracts;

\begin{tabular}{|c|c|c|}
\hline Sample name & \% Madagascar extract & \% Non-Madagascar extract \\
\hline V-MX1 & 5 & 95 \\
\hline V-MX2 & 10 & 90 \\
\hline V-MX3 & 15 & 85 \\
\hline V-MX4 & 20 & 80 \\
\hline V-MX5 & 5 & 95 \\
\hline V-MX6 & 10 & 90 \\
\hline V-MX7 & 5 & 95 \\
\hline V-MX8 & 10 & 90 \\
\hline V-MX9 & 15 & 85 \\
\hline V-MX10 & 20 & 80 \\
\hline V-MX11 & 5 & 95 \\
\hline V-MX12 & 10 & 90 \\
\hline
\end{tabular}

453

454 Another 45 samples were also prepared enriched with synthetic vanillin using 3 different 455 vanillin final concentrations:

> TOTAL VANILLIN CONCENTRATION $0.2 \%$

\begin{tabular}{|l|c|c|c|c|c|}
\hline Sample N & $\begin{array}{c}\text { Pure extract } \\
\text { Number }\end{array}$ & Pure extract & Solvent & Caramel & Vanillin \\
\hline V-AD1-Val & 1 & $85.69 \%$ & $14.28 \%$ & $0.00 \%$ & $0.03 \%$ \\
\hline V-AD2-Val & 1 & $49.95 \%$ & $49.95 \%$ & $0.00 \%$ & $0.10 \%$ \\
\hline V-AD3-Val & 1 & $35.67 \%$ & $64.20 \%$ & $0.00 \%$ & $0.13 \%$ \\
\hline V-AD4-Val & 2 & $85.69 \%$ & $14.28 \%$ & $0.00 \%$ & $0.03 \%$ \\
\hline V-AD5-Val & 2 & $49.95 \%$ & $49.95 \%$ & $0.00 \%$ & $0.10 \%$ \\
\hline V-AD6-Val & 2 & $35.67 \%$ & $64.20 \%$ & $0.00 \%$ & $0.13 \%$ \\
\hline V-AD7-Val & 3 & $89.53 \%$ & $9.70 \%$ & $0.75 \%$ & $0.03 \%$ \\
\hline V-AD8-Val & 3 & $51.23 \%$ & $46.11 \%$ & $2.56 \%$ & $0.10 \%$ \\
\hline V-AD9-Val & 3 & $36.32 \%$ & $60.28 \%$ & $3.27 \%$ & $0.13 \%$ \\
\hline V-AD10-Val & 4 & $89.53 \%$ & $9.70 \%$ & $0.75 \%$ & $0.03 \%$ \\
\hline V-AD11-Val & 4 & $51.23 \%$ & $46.11 \%$ & $2.56 \%$ & $0.10 \%$ \\
\hline V-AD12-Val & 4 & $36.32 \%$ & $60.28 \%$ & $3.27 \%$ & $0.13 \%$ \\
\hline V-AD13-Val & 5 & $89.53 \%$ & $9.70 \%$ & $0.75 \%$ & $0.03 \%$ \\
\hline V-AD14-Val & 5 & $51.23 \%$ & $46.11 \%$ & $2.56 \%$ & $0.10 \%$ \\
\hline V-AD15-Val & 5 & $36.32 \%$ & $60.28 \%$ & $3.27 \%$ & $0.13 \%$ \\
\hline
\end{tabular}


TOTAL VANILLIN CONCENTRATION 0.3\%

\begin{tabular}{|l|c|c|c|c|c|}
\hline Sample N & $\begin{array}{c}\text { Pure extract } \\
\text { Number }\end{array}$ & Pure extract & Solvent & Caramel & Vanillin \\
\hline V-AD16-Val & 1 & $89.43 \%$ & $9.69 \%$ & $0.75 \%$ & $0.13 \%$ \\
\hline V-AD17-Val & 1 & $51.18 \%$ & $46.06 \%$ & $2.56 \%$ & $0.20 \%$ \\
\hline V-AD18-Val & 1 & $36.28 \%$ & $60.22 \%$ & $3.27 \%$ & $0.23 \%$ \\
\hline V-AD19-Val & 2 & $89.43 \%$ & $9.69 \%$ & $0.75 \%$ & $0.13 \%$ \\
\hline V-AD20-Val & 2 & $51.18 \%$ & $46.06 \%$ & $2.56 \%$ & $0.20 \%$ \\
\hline V-AD21-Val & 2 & $36.28 \%$ & $60.22 \%$ & $3.27 \%$ & $0.23 \%$ \\
\hline V-AD22-Val & 3 & $89.43 \%$ & $9.69 \%$ & $0.75 \%$ & $0.13 \%$ \\
\hline V-AD23-Val & 3 & $51.18 \%$ & $46.06 \%$ & $2.56 \%$ & $0.20 \%$ \\
\hline V-AD24-Val & 3 & $36.28 \%$ & $60.22 \%$ & $3.27 \%$ & $0.23 \%$ \\
\hline V-AD25-Val & 4 & $85.60 \%$ & $14.27 \%$ & $0.00 \%$ & $0.13 \%$ \\
\hline V-AD26-Val & 4 & $49.90 \%$ & $49.90 \%$ & $0.00 \%$ & $0.20 \%$ \\
\hline V-AD27-Val & 4 & $35.63 \%$ & $64.14 \%$ & $0.00 \%$ & $0.23 \%$ \\
\hline V-AD28-Val & 5 & $85.60 \%$ & $14.27 \%$ & $0.00 \%$ & $0.13 \%$ \\
\hline V-AD29-Val & 5 & $49.90 \%$ & $49.90 \%$ & $0.00 \%$ & $0.20 \%$ \\
\hline V-AD30-Val & 5 & $35.63 \%$ & $64.14 \%$ & $0.00 \%$ & $0.23 \%$ \\
\hline
\end{tabular}

> TOTAL VANILLIN CONCENTRATION 0.35\%

\begin{tabular}{|c|c|c|c|c|c|}
\hline Sample N & $\begin{array}{c}\text { Pure extract } \\
\text { Number }\end{array}$ & Pure extract & Solvent & Caramel & Vanillin \\
\hline V-AD31-Val & 1 & $85.56 \%$ & $14.26 \%$ & $0.00 \%$ & $0.18 \%$ \\
\hline V-AD32-Val & 1 & $49.88 \%$ & $49.88 \%$ & $0.00 \%$ & $0.25 \%$ \\
\hline V-AD33-Val & 1 & $35.62 \%$ & $64.11 \%$ & $0.00 \%$ & $0.28 \%$ \\
\hline V-AD34-Val & 2 & $89.39 \%$ & $9.68 \%$ & $0.74 \%$ & $0.19 \%$ \\
\hline V-AD35-Val & 2 & $51.15 \%$ & $46.04 \%$ & $2.56 \%$ & $0.26 \%$ \\
\hline V-AD36-Val & 2 & $36.26 \%$ & $60.19 \%$ & $3.26 \%$ & $0.28 \%$ \\
\hline V-AD37-Val & 3 & $85.56 \%$ & $14.26 \%$ & $0.00 \%$ & $0.18 \%$ \\
\hline V-AD38-Val & 3 & $49.88 \%$ & $49.88 \%$ & $0.00 \%$ & $0.25 \%$ \\
\hline V-AD39-Val & 3 & $35.62 \%$ & $64.11 \%$ & $0.00 \%$ & $0.28 \%$ \\
\hline V-AD40-Val & 4 & $89.39 \%$ & $9.68 \%$ & $0.74 \%$ & $0.19 \%$ \\
\hline V-AD41-Val & 4 & $51.15 \%$ & $46.04 \%$ & $2.56 \%$ & $0.26 \%$ \\
\hline V-AD42-Val & 4 & $36.26 \%$ & $60.19 \%$ & $3.26 \%$ & $0.28 \%$ \\
\hline V-AD43-Val & 5 & $85.56 \%$ & $14.26 \%$ & $0.00 \%$ & $0.18 \%$ \\
\hline V-AD44-Val & 5 & $49.88 \%$ & $49.88 \%$ & $0.00 \%$ & $0.25 \%$ \\
\hline V-AD45-Val & 5 & $35.62 \%$ & $64.11 \%$ & $0.00 \%$ & $0.28 \%$ \\
\hline
\end{tabular}


465 Finally, the "fake" vanilla extract was used to make 15 adulterated samples as follows:

466

\begin{tabular}{|l|c|c|c|}
\hline Sample N & $\begin{array}{c}\text { Pure extract } \\
\text { Number }\end{array}$ & PVE & FVE \\
\hline V-AD46-TB & 1 & $90 \%$ & $10 \%$ \\
\hline V-AD47-TB & 2 & $90 \%$ & $10 \%$ \\
\hline V-AD48-TB & 3 & $90 \%$ & $10 \%$ \\
\hline V-AD49-TB & 4 & $90 \%$ & $10 \%$ \\
\hline V-AD50-TB & 5 & $90 \%$ & $10 \%$ \\
\hline V-AD51-TB & 1 & $50 \%$ & $50 \%$ \\
\hline V-AD52-TB & 2 & $50 \%$ & $50 \%$ \\
\hline V-AD53-TB & 3 & $50 \%$ & $50 \%$ \\
\hline V-AD54-TB & 4 & $50 \%$ & $50 \%$ \\
\hline V-AD55-TB & 5 & $50 \%$ & $50 \%$ \\
\hline V-AD56-TB & 1 & $80 \%$ & $20 \%$ \\
\hline V-AD57-TB & 2 & $80 \%$ & $20 \%$ \\
\hline V-AD58-TB & 3 & $80 \%$ & $20 \%$ \\
\hline V-AD59-TB & 4 & $80 \%$ & $20 \%$ \\
\hline V-AD60-TB & 5 & $80 \%$ & $20 \%$ \\
\hline
\end{tabular}

467 PVE: pure vanilla extract; FVE: "fake" vanilla extract

468 In total, 60 adulterated vanilla in house admixtures were prepared.

469

470 
Supplementary Figure 1. Loading plot from PLS-DA models for the scenario 1: purity: (a) NIR, (b) MIR and (c) Raman

a

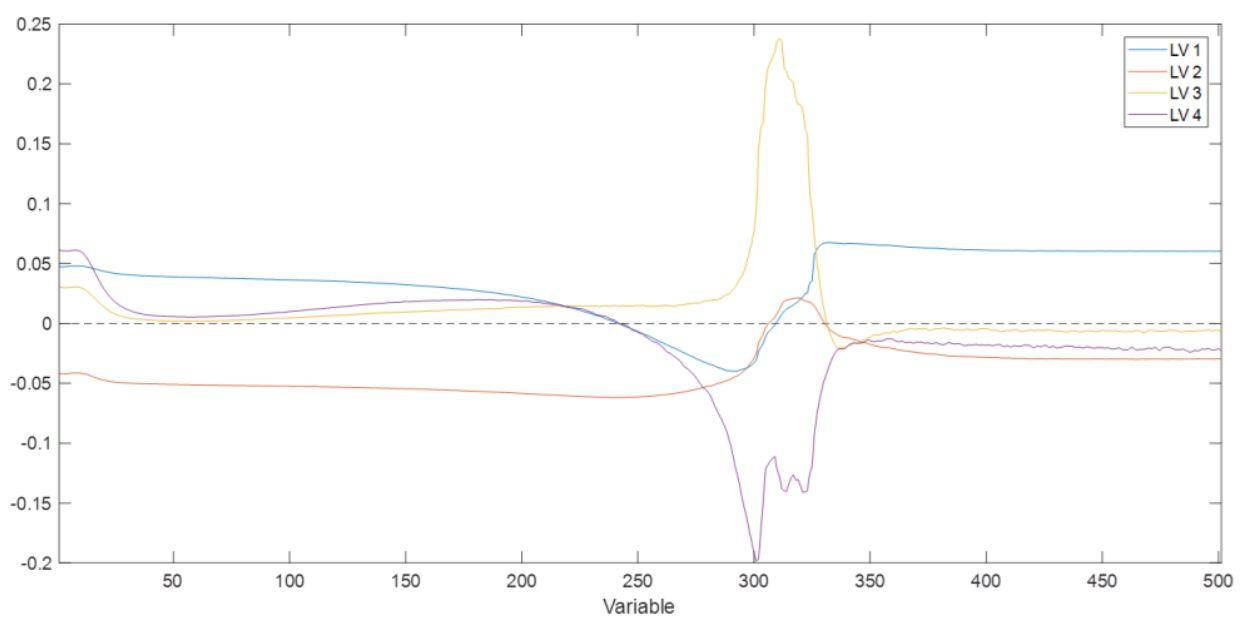

b

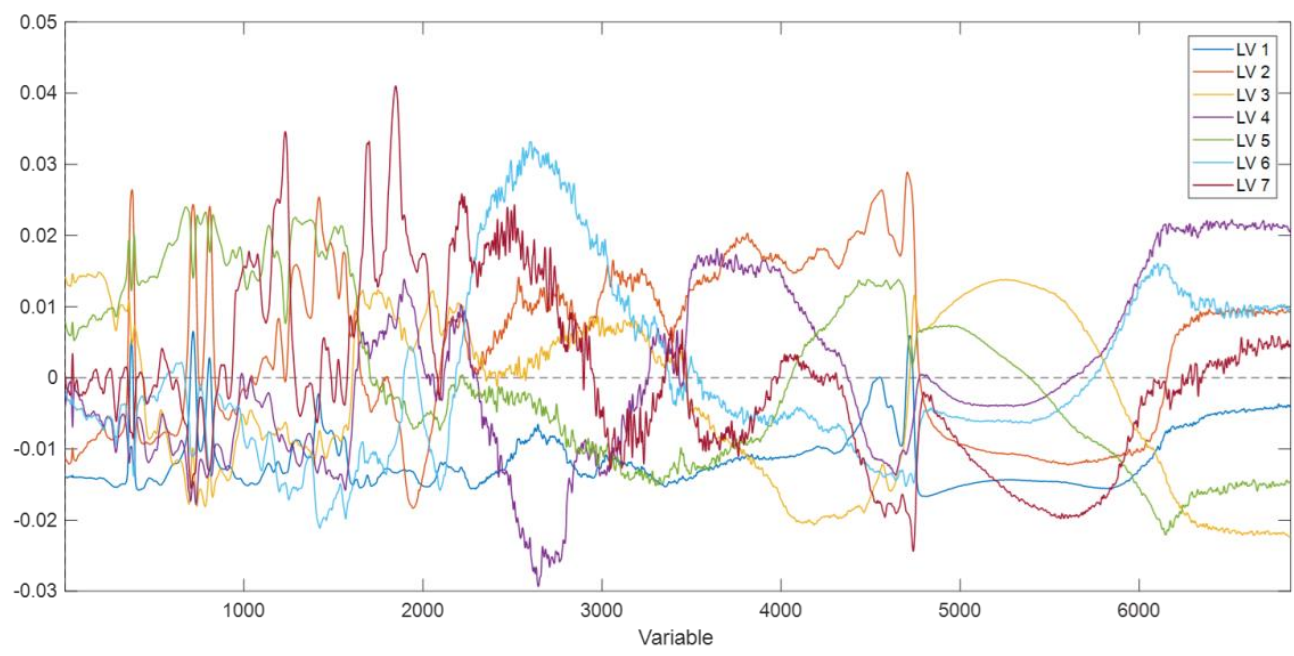

C

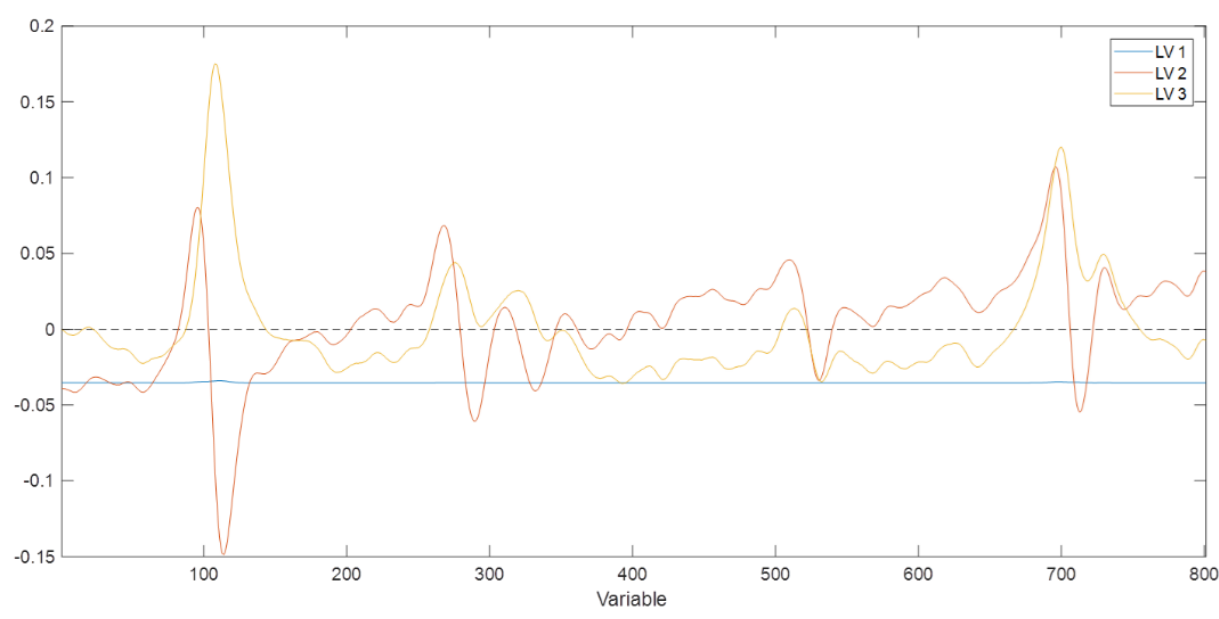


Supplementary Figure 2. Classification plot from PLS-DA models for the scenario 1: purity: (a) NIR, (b) MIR and (c) Raman

a

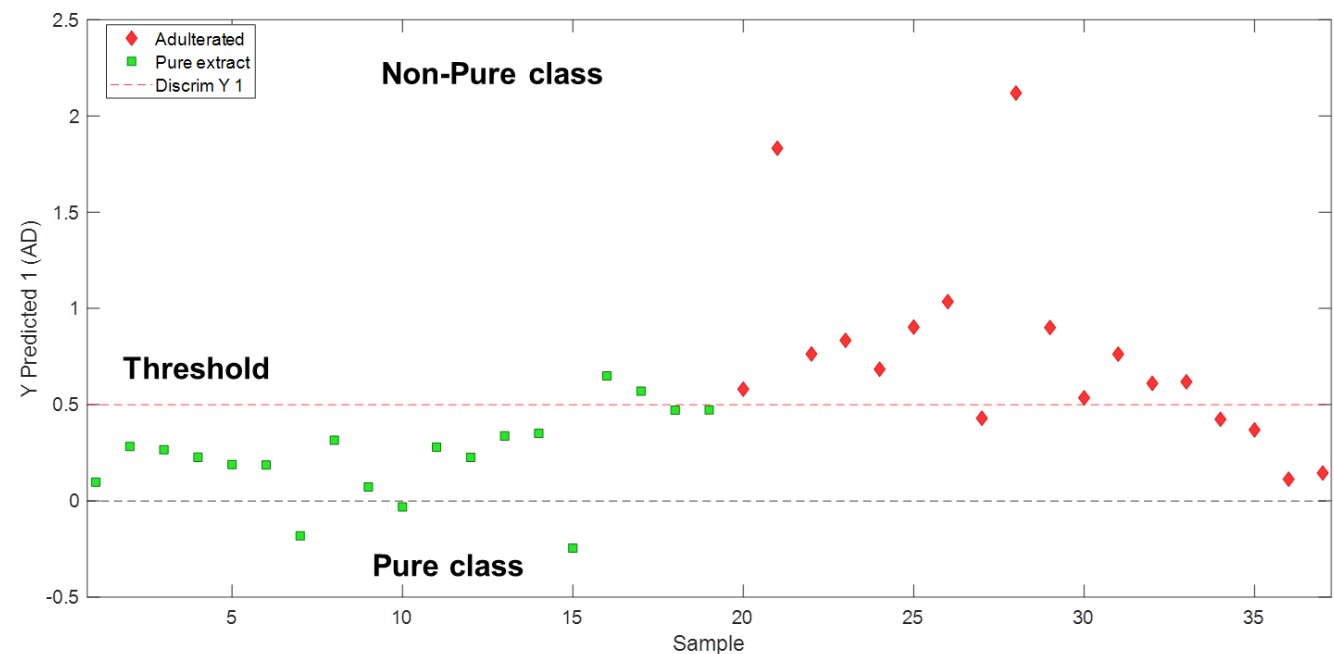

b

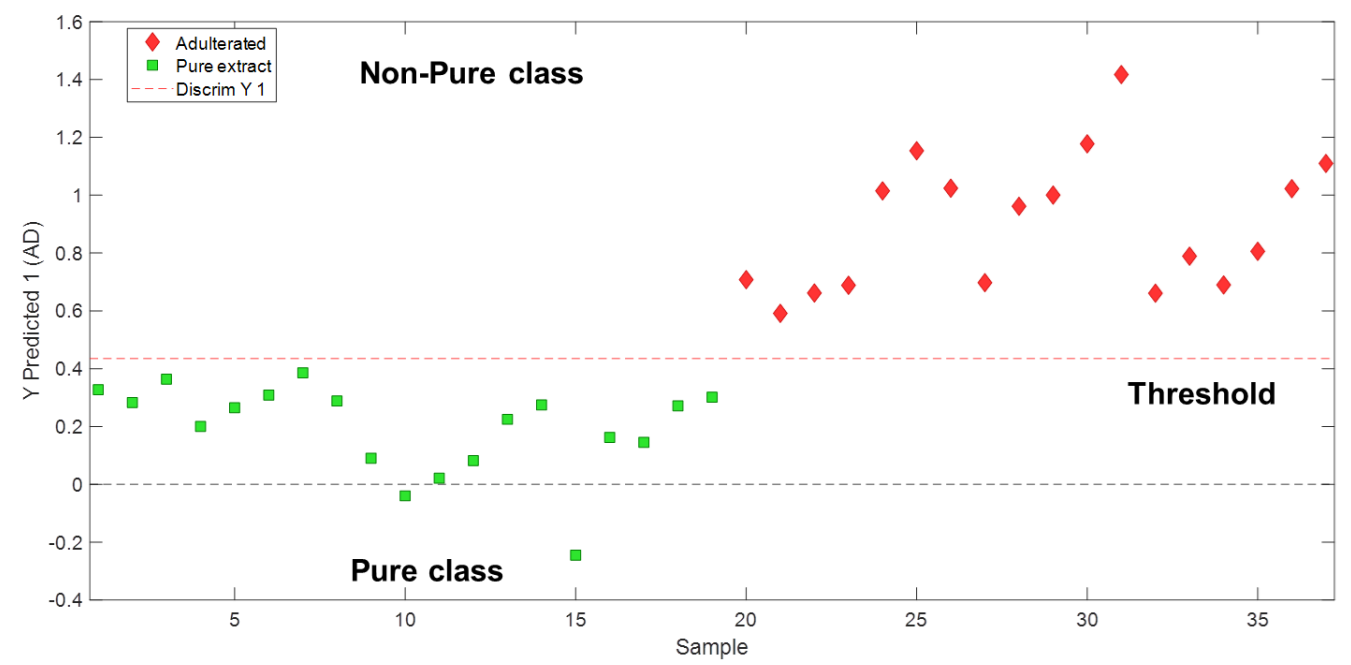

C

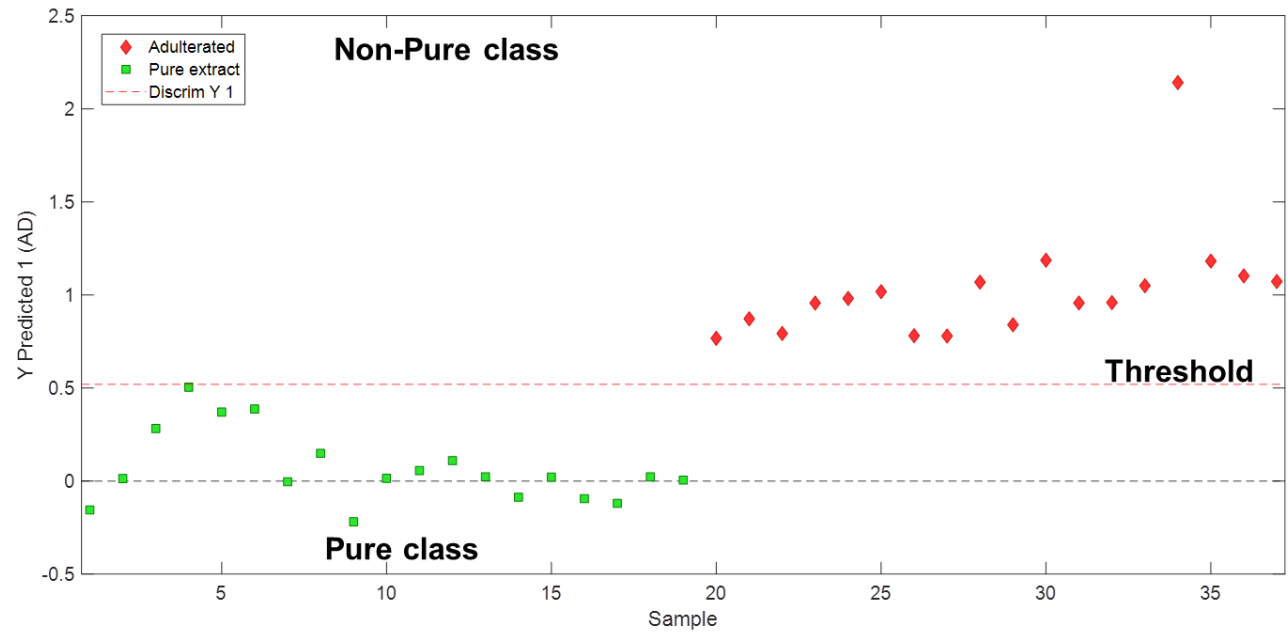


Supplementary Figure 3. Loading plot from PLS-DA models for the scenario 2: origin: (a) NIR, (b) MIR and (c) Raman

a

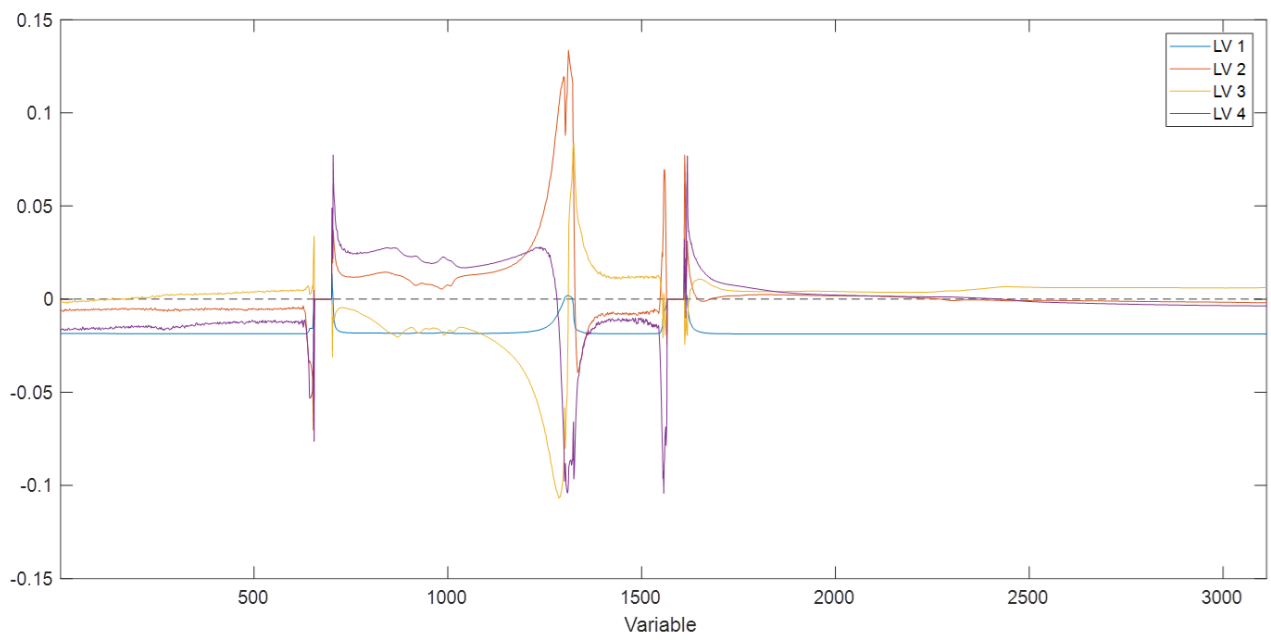

b

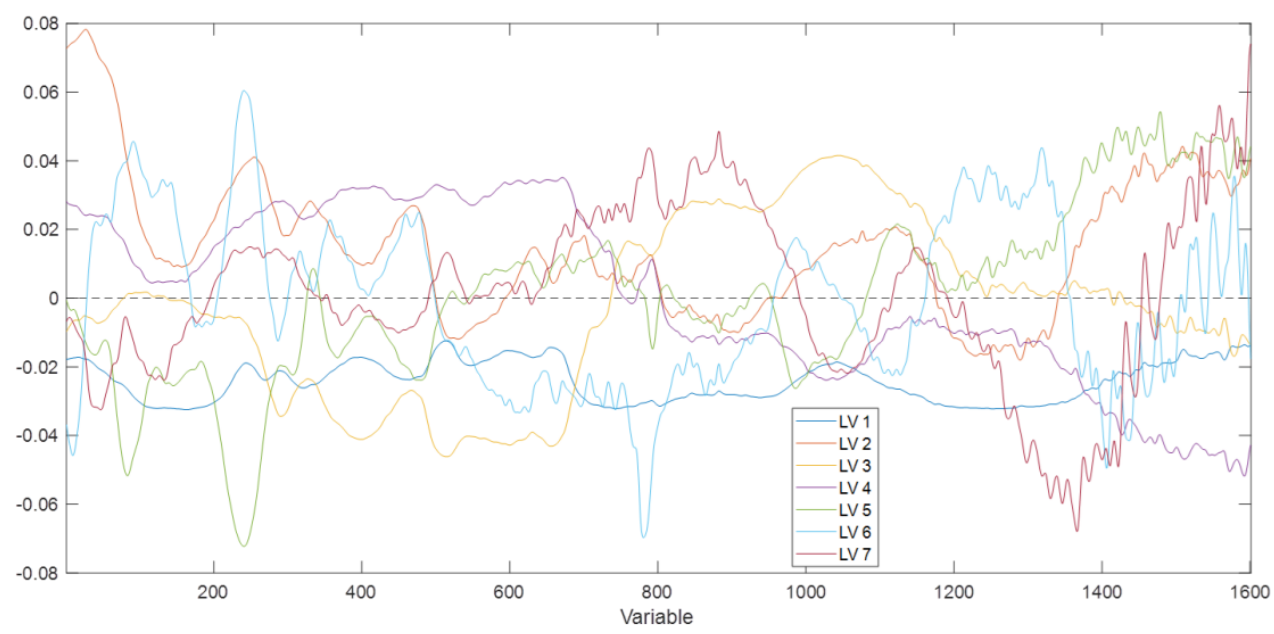

C

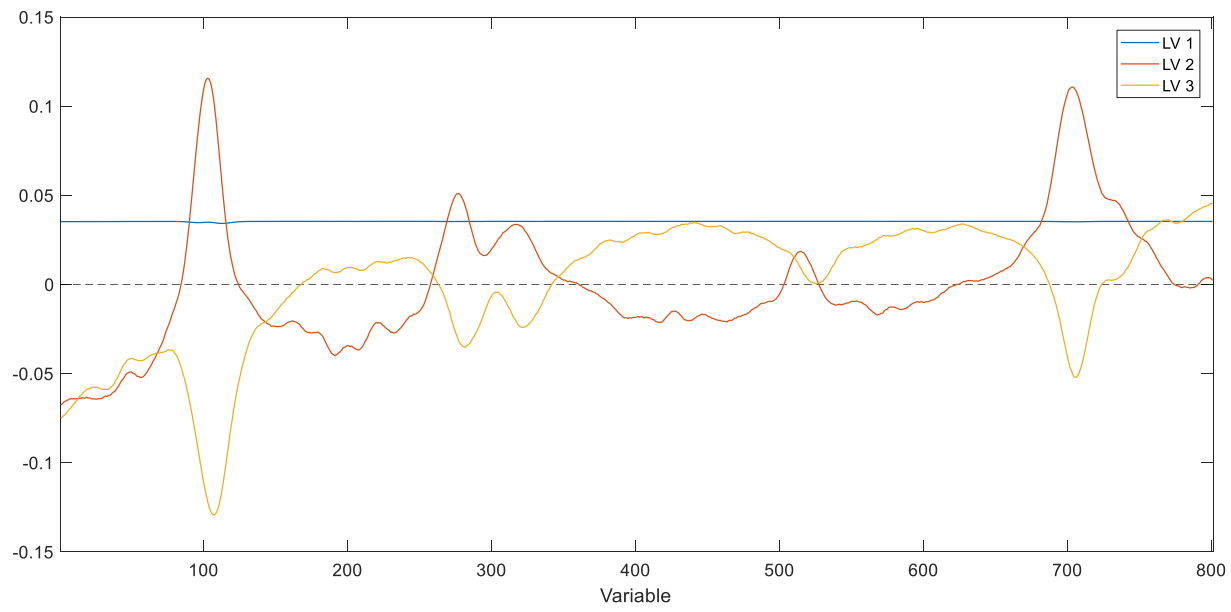

